\title{
Subcategories of the Shona Subject Relation
}

\author{
Maxwell Kadenge
}

\author{
Department of Linguistics, University of the Witwatersrand \\ maxwell.kadenge@wits.ac.za
}

Isaac Mhute

Department of Languages and Media, Zimbabwe Open University isaacmhute@gmail.com

\section{Doi:10.5901/mjss.2014.v5n27p1621}

\begin{abstract}
The article falls under the broad area of syntax and seeks to analyse the subcategories of the subject relation in Shona, a southern Bantu language spoken mainly in Zimbabwe. We assess types of words and phrases that can function as subjects in this language. Our findings show that there are seven subcategories of the subject relation in Shona. The main conclusion that we make is that in Shona mainly noun phrases perform the subject function and in situations where the subject is some piece of old information non-noun phrases do.
\end{abstract}

Keywords: syntax; subcategories; subject; noun phrase; Shona

\section{Introduction}

The article falls under the broad area of Shona syntax and it seeks to analyze the syntactic notion of subject relation in Shona, using the projection principle and selectional principles established in well-studied languages. It assesses types of words that can function as subjects in the Shona language. It is noteworthy that the notion of grammatical relations is controversial. Chomsky (1981) and Gazdar (1985) say that decades have lapsed with the notion on the tables. Scholars do not agree on what constitutes basic concepts in syntax like subject and predicate (Langacker 1991). Hence, Langacker (1991) concludes that scholars' views in the area are as many as the languages of the world. These scholars, though they do not refute the view that the grammatical notions like subject relation are language universal, they agree that the notions are developed in the respective languages and their behaviour varies from language to language.

Some scholars argue that grammatical notions are far from being language universal. For example, Cook (1988), Robins (1991) and Tarugarira 1996) claim that the notion has remained vague for so long due to presuppositions. For instance, they note that it is in fact a presupposition that all languages have grammatical relations. Tarugarira (1996) argues that linguists have based conclusions in the area on implicational universals. Implicational universals are universal conclusions based on researches in certain languages and can be nullified by the discovery of a different behaviour in one language. Other scholars claim that grammatical relations are language universal. For example, Mohanan (1988: 230) argues that grammatical 'relations are a property of the structure of all natural languages of the world and every language exhibits some fundamental processes dependent on them'. In the same vein, Bresnan (1982) says that grammatical functions are universal primitives of syntax, not derived from phrase structure representations or from semantic notions. Bresnan notes that grammatical functions are lexically encoded in predicate argument structures (PASs) of all languages in varying ways and constituent structure categories are universally decomposed into features. Grammatical functions are syntactically encoded directly in surface representations of phrase structure, according to structuring configurations or morphological features. Mohanan (1988) describes grammatical relations as a universal notion whose different ways of realization are currently acting as the basis for the typological distinction between configurational and non-configurational languages. Likewise, Everaert, Van Riemsdijk, and Goedemans (2006) observe that in contrastive linguistics the subject was first defined to be the main argument of a proposition and since then, linguistic theories have been developed to describe it in languages all over the world. This article was motivated by the fact that the Shona subject relation has not received significant attention in previous studies. Our main aim is to identify and characterize the sub-types of the Shona subject relation.

Shona is a southern Bantu language that is spoken as a home language by about $75 \%$ of Zimbabweans. It is also 
spoken in neighbouring countries such as Botswana and Mozambique. We analyze the Shona subject relation using the projection principle. The projection principle is a sub-branch of government and binding (GB) theory (Haegeman, 1998), the central idea of which is that lexical items heading constructions must dictate the number and type of lexical items to take part in the construction. Our main concern is on the specifications of the predicates involved. In each example the predicates have their predicate argument structures as well as the features of the arguments specified. The following sections identify and characterize subject sub-types and the lexical items that play the role of the subject in the Shona language. All the examples that are analyzed in this article are from the authors who speak both Karanga and Zezuru, the main dialects of the Shona language.

\section{Topical Subject}

Lee (1974) and Lappin, Levine and Johnson (2000) observe that the basic sentence for a Subject Verb Object (SVO) language can be described as comprising a subject (topic) and a predicate (comment). The topic acts as the pragmatic focus. It is the most pronounced argument or participant in a piece of discourse. In simple terms, it is what the conversation is all about. Languages have different ways of attaching prominence onto their participants. For instance, Kuno (1973) says Japanese places an article immediately after an argument to attain this effect. Shona places a participant in the sentence-initial position in order to give it prominence. Once a word occurs there, it automatically becomes the topical subject of that sentence (Hale \& Keyser 2002). For example, for one to attach prominence onto the Shona NP mbudzi 'goat' in (1) there is need to employ the rule that derives (2):

(1) Farai u-a-uray-a mbudzi Farai wauraya mbudzi

Cl1a.-Farai Cl1a.Agr.-Pst-kill-Tv Cl9.- goat

uraya <Agent Theme >

Farai $\quad[+H U M A N,+S I N G U L A R]$

Mbudzi [+ANIMATE, -HUMAN, +SINGULAR]

'Farai killed a goat.'

In (1) the most prominent entity is the noun Farai since it is the occupant of the topical or sentence-initial gap. It is the topical subject in the sentence. To shift prominence to mbudzi 'goat' the passive transformation in (2) is triggered:

(2) mbudzi i-a-uraw-a naFarai mbudzi yaurawa naFarai

Cl9.-goat Cl9.Agr-Past-killed-Tv Cl1a.-Farai

urawa <Theme>

Farai [+HUMAN; +SINGULAR]

'a goat has been killed by Farai.'

In example (2) the subjectivisation or subject raising process demotes the semantic subject Farai to the role of an oblique object thereby promoting mbudzi 'goat' to a topical subject position. This process follows the demands of the projection principle that no two entities can be assigned the same role in a sentence. In Shona, a topical subject occupies the canonical subject position and all non-subject participants of a sentence may become topical subjects and prominent sentential entities through subjectivisation. The subject is, therefore, a type of status that is imposed onto an argument by changes in word order. That makes the status a characteristic of the surface structure.

\section{Morphological or Grammatical Subject}

The morphological or grammatical subject appears to be the other name for a topical subject in Shona. This is because a grammatical subject refers to the participant that controls agreement in a sentence, a task normally assigned to topical subjects in Shona. In a sentence, once that agreement is missing, ungrammaticality results leading to the term grammatical subject being used synonymously with morphological subject (Brown \& Miller, 1985). Stockwell (1977) defines agreement as a type of constraint on the form of words occurring together. It requires that one form be altered to match the form of the other. In Shona, this effect is attained by placing morphological markers belonging to the class, number and person of the controlling subject phrase onto the verbal complex as shown in (3) below:

(3) va-nhu va-Ndanga va-rim-a ma-bagwe vanhu vaNdanga varima mabagwe

Cl2.-people Cl2.Agr Cl1a-Ndanga Cl2.Agr.-grow-Tv Cl6.- maize

rima < Agent Theme >

vanhu vaNdanga $\quad$ [+HUMAN; -SINGULAR]

mabagwe [-ANIMATE, -SINGULAR; -ABSTRACT]

'Ndanga's people have grown maize' 
In Shona, agreement is controlled by a participant occupying the sentence initial position like vanhu vaNdanga 'Ndanga's people' in (3) above. It controls agreement by placing the class 2 marker va- 'have' onto the verbal complex varima 'have grown', making it the topical subject.

\section{Dummy Subjects}

According to Stockwell (1977), there is one group of languages with well-marked person, number and class affixes in verbs. The languages may omit subjects that are transparent in the context or in the verbal complexes of sentences. There are also other languages whose verbal markings of the subject role are less conspicuous and in these, the inclusion of the subject relation becomes obligatory. When this obligatoriness extends into contexts where no real subject makes sense, there rises the need for what are known as dummy fillers or dummy subjects. These are placeholders because they do not refer to any entity one can come across in the real world. Huddleston and Pullum (2005:43) identify two types of these, namely, 'expletives' and 'catastrophic it'. According to Huddleston and Pullum (2005), expletives are words like 'it' or 'there' in English when they do not refer to anything and the Shona equivalent is ku- as shown in (4) below:

(4) ku-no-nay-a. kunonaya

Cl15.-Pres Cont Tense-rain-Tv

naya <Theme Locative>

'It rains.'

Unlike the English expletive 'it' which does not have a referent, the Shona one in (4) has it in external world which is the location in which the raining is taking place. The Shona 'it' is a proclitic and its host is the verb kunonaya. In fact, Shona has two types of positional clitics, those which lean forward in the following word, like the expletive ku- in (4), called proclitics, and those which lean backwards on the preceding word, called enclitics. The Shona equivalent of the 'cataphoric it' is zvi- 'it' and it is co-referent with a subordinate clause that comes after it as shown in (5) below:

(5) zvi-no-zivikanw-a zvinozivikanwa

Cl8. Pres Cont Tense-known-Tv

zivikanwa <Patient>

'It is known by everyone.'

In (5) above zvi- 'it' co-refers with the statement that follows the whole expression. In other words, it co-refers with that which is known. Clearly, Shona is one of those languages with well-marked person, number and class affixes in their verbal complexes because, one can, for instance, have a covert subject as illustrated in (6) below:

(6) va-a-rim-a ma-bagwe varima mabagwe

Cl2.-Pst-grow-Fv Cl6.-maize

rima <Agent Theme>

va- $\quad$ [+HUMAN; -SINGULAR]

mabagwe [-ANIMATE; -ABSTRACT; -SINGULAR]

'they grew maize'

In example (6) va- 'they' is the agreement marker which is in agreement with a covert subject. This sentence is only acceptable if the covert subject is known to the listener. Acceptability here is taken to mean that something is correct in as far as the judgment of a native speaker is concerned. However, when the obligatoriness of subjects extends into contexts where no real subject semantically suits the environment appropriately, in Shona the speakers make use of dummy subjects as shown in (7) below:

(7) zvi-no-fadz-a ku-gar-a mu-rugare zvinofadza kugara murugare

Cl8. Pres Tense-make happy- Fv Cl15.-stay-Fv Cl18.-peace

fadza < Source Experiencer >

kugara murugare [-ANIMATE, +ABSTRACT]

'it is interesting to stay in peace'

In example (7) zvi- 'it' acts as a dummy subject or filler. It is serving a purely grammatical function in this sentence. In Shona dummy fillers are used but only in the form of proclitics and/or prefixes bound onto verbal complexes. The predicate argument structure of example (7) has two participants because though omitted the experiencer is still projectable. 


\section{Semantic or Thematic Subject}

The semantic or thematic subject is the underlying or obligatory subject. Semantic subject is the type that is encoded as a subject at the lexical functional level or at the deep structure level of a particular sentence. Its status is, thus, projected from the thematic level of grammar. It is the obligatory or inaccessible subject. This explains why the participant encoded as the semantic subject cannot be demoted from the status by any rule at the surface structure level. It can only be either promoted to or demoted from the topical or grammatical subject status but never from its original status as the semantic or thematic subject. Furthermore, no other participant can be promoted to the semantic subject status at the level of surface structure. It has no substitute. It is this characteristic that earns it the term 'obligatory subject'. It is noteworthy that it is only in cases where the semantic, grammatical and/or the topical subject status are found encoded in one entity that the sentence is referred to as a prototypically transitive sentence, as shown in (8) below:

(8) Shorai u-a-rov-a mu-ana u-ake Shorai warova mwana wake

Cl1a.-Shorai Cl1aAgr-Pst-beat-Fv Cl1.-child Cl1.Poss-hers

rova <Agent Patient>

Shorai [+HUMAN, +SINGULAR]

mwana wake [+HUMAN, +SINGULAR]

'Shorai beat her child.'

Example (8) is a typical transitive sentence with Shorai an Agent and mwana wake 'her child' a Patient. It has thematic roles at the extreme ends of the continuum characterizing the thematic hierarchy. The discourse of transitivity is all about the ability of a predicate to take its external and internal arguments as stipulated in its lexical entry and emphasized by the projection principle. Williams (1988) describes internal arguments as realized internal to the maximal projection that the verb heads, and external arguments as realized outside the maximal projection. The semantic subject is also the thematic subject in the sense that the two selectional principles, that is, the thematic hierarchy (TH) and the semantic reasons, coincide in their selections. They both capture the flow of action as it is presented at the thematic structure level of syntax. Thematic subject is one selected by the principle of the thematic hierarchy. This involves a ranking of thematic relations in a hierarchy running from Agent to Location as follows:

(9) Agent $>$ Beneficiary or Benefactor $>$ Maleficiary or Malefactor $>$ Source $>$ Goal $>$ Experiencer $>$ Instrument $>$ Theme or Patient $>$ Location

The higher an entity ranks on the hierarchy the higher the preference to subjecthood. This means that if a sentence has an Agent and Patient as its participants, the Agent becomes the automatic subject of the sentence.

\section{The Intransitive Subject}

The intransitive subject is the solitary argument in an intransitive sentence such as John in example (10) below:

(10) John u-a-f-a John wafa

Cl1a.-John Cl.1a Agr.-Pst-die-Fv

Wafa <Theme >

John [+HUMAN, +SINGULAR]

'John has died'

In (10), John is the solitary participant that is involved in the sentence. It automatically becomes the subject and controls agreement in the sentence. This satisfies the requirements of the extended projection principle which demands that every sentence must have a subject of some sort. This observation satisfies the intransitivity assumption (Hopper and Thompson, 1982) that demands that where there is a solitary argument, no matter what its thematic role is, it becomes the automatic subject.

\section{Typical Phrases for Shona Subjecthood}

The main aim of this section is to identify and present the types of lexical items to which the Shona subject relation is typically assigned. Langacker (1991) points out that in most languages a prototypical subject is a noun phrase. Similarly, Everaert, van Riemsdijk and Goedemans (2006) discuss different types of subject phrases in detail. A typical example is a determinerless noun phrase, also called a bare noun phrase. This is mostly limited to plural noun phrases and noun phrases headed by a mass noun such as vavaki 'builders' in (10) below:

(11) va-vaki va-ri ku-shanda vavaki vari kushanda

$\mathrm{Cl}$ 2.- builders $\mathrm{Cl} 2$ Agr-Aux-is Cl15-work 

vari
$<$ Experiencer>
vashandi [+HUMAN; +PLURAL]
'builders are at work.'

\section{Noun Phrases and the Shona Subject Role}

Cross-linguistically, noun phrases are usually assigned the subject role. All the examples presented above confirm this observation to a large extent. Here are more exampels:

(12) ivo va-nhu va-rwira sadza ivo varwira sadza

Cl2.-Pron Cl2.-people Cl2Agr-fight for-Tv Cl5.- sadza

ivo vanhu NP Subject - pronoun + noun - qualifier

rwira < Agent Patient>

ivo vanhu [+HUMAN, -SINGULAR]

sadza [-ANIMATE, -ABSTRACT; +SINGULAR]

'they the people fought for sadza.'

In (12) above ivo vanhu 'they the people' is a noun phrase with vanhu 'people' and ivo 'they' occurring as pronoun and noun in apposition.

(13) ivo va-nhu va-inyu va-ba doro ivo vanhu venyu vaba doro

Cl2-Pron Cl2-people Cl2Poss Cl2Agr -steal-Tv Cl5-beer

ivo vanhu venyu NP Subject --------- Pronoun + Noun + Possessive

vaba < Agent Patient >

ivo vanhu venyu [+HUMAN, -SINGULAR]

doro [-ANIMATE, -ABSTRACT]

'they your people stole beer.'

In (13) above the NP subject ivo vanhu venyu 'they your people' is a noun phrase that has the combination of a pronoun ivo 'they', possessive venyu 'your' and noun vanhu 'people'. This is an acceptable combination for an NP.

(14) mu-kadzi mu-royi u-a-ba mu-ana mukadzi muroyi waba mwana

Cl1-woman Cl1-witch Cl1Agr-Pst-steal-Tv Cl1- child

mukadzi muroyi NP Subject - noun and adjective in apposition

waba <Agent Patient>

mukadzi muroyi $\quad$ [+HUMAN; +SINGULAR]

mwana [+HUMAN; +SINGULAR]

'a female witch stole a child.'

The subject in (14) is an NP made up of a noun mukadzi 'female' and an adjective muroyi 'witch' occurring in apposition. It is again an acceptable combination for a Shona NP.

(15) Munya u-a-tor-a banga Munya watora banga

Cla 1-Munya CL1Agr-take- Tv 'knife'

Munya NP Subject -------- Noun - Qualifier

tora < Agent Patient >

Munya $\quad[+$ HUMAN, + SINGULAR]

banga [-ANIMATE, -ABSTRACT, +SINGULAR]

'Munya took a knife.'

In example (15) above Munya is an NP subject. NPs made up of nouns without qualifiers are also acceptable in Shona suggesting that the subject role is typically assigned to the various NP types in the language. However, the language allows non-NPs as subjects both in isolation and in combination as is demonstrated in the next section.

\section{Non-NPs and the Shona Subject Role}

In this section we look at subjects that are non-NPs in Shona. Consider the following Shona sentences:

(16) imwe i-a-enda ku-musha imwe yaenda kumusha

Cl9-another one Cl9Agr-go-Tv Cl15-home

imwe non-NP Subject ---------- enumerative

enda $\quad$ Agent Goal>

imwe [+ANIMATE; +SINGULAR] 
kumusha [-ANIMATE; -ABSTRACT]

'another one has gone home.'

This is an acceptable Shona sentence with imwe 'another one', an enumerative, playing the role of the subject. It is not an NP. It can be regarded as an enumerative phrase of some sort.

(17) tsvuku i-agut-a doro tsvuku jaguta doro

Cl9 Adj-red one Cl9 Agr- Pst-satisfy-Tv Cl15-beer

tsvuku non-NP Subject --- adjective

guta <Experiencer Source>

tsvuku [+ANIMATE; +SINGULAR]

doro [-ANIMATE; -ABSTRACT]

'the red one has had enough beer.'

(18) iyi ne-iya nde-dzi-angu iyi neiya ndedzangu

CL9DEM. conj. CL9SEL. COPPL. POSS.

iyo neiya non-NP Subject combination --- demonstrative + selector

iyi neiya [+ANIMATE; -SINGULAR]

'this one and that one are mine.'

Example (17) has an adjectival subject tsvuku 'red one' whereas (18) has a combination of a demonstrative and selector iyi neiya 'this one and that one'. Both of them are grammatical and acceptable. However, examples (16), (17) and (18) are only understood as complete statements if looked at in their respective or known contexts. Such sentences are common in day-to-day conversations - suggesting that not only NPs perform the subject role in Shona. Hence, Fortune (1959) observes that constructions belonging to the constituent class of Shona subjects are substantive phrases, compound substantive phrases, and conjunctives plus substantive phrases, a statement that does not restrict the role of the subject relation exclusively to NPs.

It is worth stressing that such non-NPs, whether in isolation or in combination, make complete sense as subjects if and only if the referent subject is some piece of old information. In this case, the subject is an enumerative occurring in isolation. In other words, there are covert nouns qualifying the non-NP substantives. The sentences are only acceptable as a result of the flexibility of the language in question. For instance, imwe 'another one' in (16) can be referring to a goat or cow. In (17) tsvuku 'the red one' refers to the colour of a covert noun. It is this noun that qualifies the non-NP in the deep structure of the sentence. Therefore, at surface structure level, non-NPs qualify to act as subjects in Shona but at the deep structure level only NPs perform the function.

\section{Conclusion}

In sum, in Shona, we have topical subjects (occupying the sentence-initial gap), morphological subjects (controlling sentential agreement), Thematic or semantic subjects (higher on the thematic hierarchy), Intransitive subjects (sole participant in an intransitive sentence) as well as a dummy subjects (a place holder in a sentence where no real subject is semantically appropriate). Typical subjects are NPs in Shona. However, in cases where the subject constitutes some piece of old information, non-NP entities may play the role both by their selves or in combinations. It came out as well that in such sentences the non-NP subjects are only a characteristic of the surface structure. They have their deep structure NP subjects whose noun heads are omitted at the surface structure level due to the language's flexibility and the desire to avoid repetition since such a process is only permissible when the noun is a piece of old information. All in all, therefore, it is difficult in Shona to identify one single selectional principle that caters for all sentence types which gives rise to the seven subject sub-categorizations that we have identified. There is no one type of word that serves as the subject for all the possible Shona sentences. NPs and non-NPs substantives can play the role both in isolation and in combinations. However, it is noteworthy that the non-NPs can only play the role if and only if their referent is some piece of old information that needs not be repeated.

\section{References}

Brown, E.K. \& Miller, J.E. 1985. Syntax: A linguistic introduction to sentence structure. London: Happer Collins Academic. Chomsky, N. 1981. Lectures on government and binding theory. Dordrecht: Foris.

Cook, V. 1988. Parameters syntax. New York: St. Martins Press.

Everaert, M.; van Riemsdijk, H. \& Goedemans, R. 2006. The Blackwell companion to syntax, I-V, Blackwell, London.

Fortune, G. 1959. A preliminary survey of Bantu languages of the federation. Communication: The Rhodes Livingstone Institute 14:59- 
67.

Hale, K. \& Keyser, J. (2002). Prolegomena to a theory of argument structure. Linguistic Inquiry Monograph 39: 43- 56.

Haegeman, L. 1998. Introduction to government and binding theory. Oxford UK \& Cambridge USA: Blackwell Publishers.

Hopper, P.J. \& Thompson, S.A. 1982. Syntax and semantics 15: studies in transitivity. New York: Academic Press.

Huddleston, R. \& Pullum, K. 2005. A student's introduction to English grammar. Cambridge: Cambridge University Press.

Hyman, L.M. \& Duranti, A. 1992. On the object relation in Bantu, in Syntax and Semantics: Studies in Transitivity edited by P. Hopper \& S.A. Thompson. NewYork: Academic Press: 218-238.

Kuno, S. 1973. The structure of the Japanese language. Cambridge, Mass: MIT Press.

Langacker, R.W. 1991. Foundations of cognitive grammar: 2: Descriptive application. Stanford: Stanford University Press.

Lappin, S., Levine, R. \& Johnson, D. 2000. "Topic ... Comment". Natural Language and Linguistic Theory 18:665-671.

Lee, B.D. 1974. The semantics of Inibalo verbal affixes. Lingua 34:181-218.

Mohanan, T. 1988. Cauzativisation in Malayalam. California: Stanford University Press.

Robins, R.H. 1991. A short history of linguistics. London: Longman.

Siewierska, A. 1991. Functional grammar. London and New York: Routledge.

Stockwell, R. P. 1977. Foundations of syntactic theory. New Jersey: Prentice-Hall Englewood Cliffs.

Tarugarira, J. 1996. Subject relation in Shona. Unpublished honours dissertation, Linguistics Department, University of Zimbabwe.

Williams, E.1988. Argument structure and morphology. The Linguistic Review 1: 81-114. 